\title{
Web Based Application for Supporting Knowledge Sharing at Cipadu Village
}

\author{
Dian Anubhakti, Basuki Hari Prasetyo, and Nazir Harjanto, Member, IACSIT
}

\begin{abstract}
Web-based applications is now a necessity especially in terms of information dissemination. Further, the application is a web-based tool that can increase the business value that characterizes economic competitiveness. The Cipadu village is a center of businesses engaged in the sale of clothing and apparel, but the marketing and dissemination of information among the public is done traditionally. The problem is there is no information about their other markets. Therefore, this paper presents the application of web-based knowledge sharing within the community groupware Cipadu, so marketing the product as well as the dissemination of information among people and institutions outside the Cipadu village also can be create for people at Cipadu. The application of knowledge sharing application in Cipadu can support web-based communication in storing, distributing, and accessing knowledge from other villages or government agencies, so that a culture of knowledge sharing in this village will be usefull.
\end{abstract}

Index Terms-Knowledge sharing, web-based application, Cipadu village.

\section{INTRODUCTION}

In the globalization era, which will be marked with economic competitiveness, the use of computer networking and data communication become a character of economic competitiveness. Global competitiveness will very fast arise, but generally in Indonesia, it is still in the early stages of this process and still tries to find a model on how to be a competitive country. The effective and efficient way for competitiveness is to develop network and communication. These efforts can be reached by using Information and Communication Technology (ICT) and knowledge management. In the era of knowledge-based economy, the rise of knowledge considered as an increase of competitiveness. Therefore, knowledge becomes an asset of a company/enterprise. In supporting the Government efforts of developing economic competitiveness we did a survey in Cipadu. Cipadu is a famous village that produces materials for clothing and sells them to Cipulir market. This village is only $10 \mathrm{~km}$ from Cipulir market. Therefore, the village people want to enhance their market to Tanah Abang market, the biggest clothing market in Jakarta. It means that they have to develop a communication tools and we propose a web-based communication for knowledge sharing means.

Unfortunately, Cipadu village do not have web-based or data communication, database and computer network facilities, even data and information still be stored manually. It means Cipadu needs application and database for storing, distributing, and accessing knowledge from other village or agencies, thus sharing knowledge and knowledge creation is formed. Therefore, data Communication should be built in the form of web-based. Cipadu can't connect to the global market to introduce their product, especially for clothing product. In order to open the market nationally or internationally, we propose to develop an e-commerce website include database for Cipadu product and service. This website is not only opening or accessing information, but also to support the village knowledge sharing. Their website advertises products and services, and may provide a means for taking orders. Small businesses could use the knowledge sharing network in selling their product and services.

The development of knowledge management must make provision for both direct human knowledge and indirect human knowledge, as mediated by machines, which extend and enhance the powers of mind or tacit knowledge. Therefore, knowledge management should be directed to make knowledge accessible and useful. This is one of the usefulness of village database, which data, information, and village knowledge easily accessed by everyone. Through externalization and internalization, in the Nonaka' Knowledge Cycle Model", network becomes important for the village people [1]. By developing simple network, the people easily access outside knowledge and know how to do something of value to the village. This knowledge should become skill knowledge. Skill of know-how in knowledge on doing something, become a value and important competencies [1]. By this, it means that valuable skill or knowledge should follow the rapidly changing business environment, in order to come to the market needs. The market needs also means the people of Cipadu needs and mostly means how to communicate with other villages through their web-based communication. They can get benefit from this communication, since they receive valuable new knowledge and also they have the opportunity to create knowledge from the information they receive through daily communication.

The rest of this paper describe the following: Section II research method, Section III Impact of application knowledge sharing web based on village people standard of life, Section IV result and analysis, and closed by conclusion in Section V.

\section{Research Method}

The authors are with the Faculty of Information Technology, University of Budi Luhur, Jakarta, Indonesia (e-mail: dian.anubhakti@gmail.com, haribhopal01@yahoo.com, nazirharjanto@yahoo.com).
The data communication in Cipadu village, focus on e-commerce web-based, as e-commerce conduct business on 
the Web. By using knowledge sharing through the online knowledge web application, village people have broad communications, especially for Cipadu village, other villages, markets, and other government agencies. Today, even the smallest computers can communicate directly with one another, with hundreds of computers on a company network, or with millions of other computers around the world - often via internet [2]. Therefore, in the web, it should also be included posting of knowledge in order to create a new knowledge.

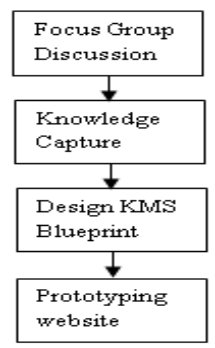

Fig. 1. Knowledge sharing process.

The knowledge sharing process at Cipadu village, shown in Fig. 1, first the head of the village should develop Focus Discussion Group (FGD) which related to the capture of FGD result in order to design Knowledge Management System and implementation web based application for supporting knowledge sharing.

However International Agencies have already reviewed the benefit of Sri Lanka' e- village model [3] and Cipadu village people can learn from this model. The Sri Lanka' e-village model have six main steps, which are 1) Relationship building, 2) Installation of Equipment, 3) Training and Workshops, 4) Implementation of Educational Plan, 5) Other services to the Community and 6) Mesh Technology implementation.

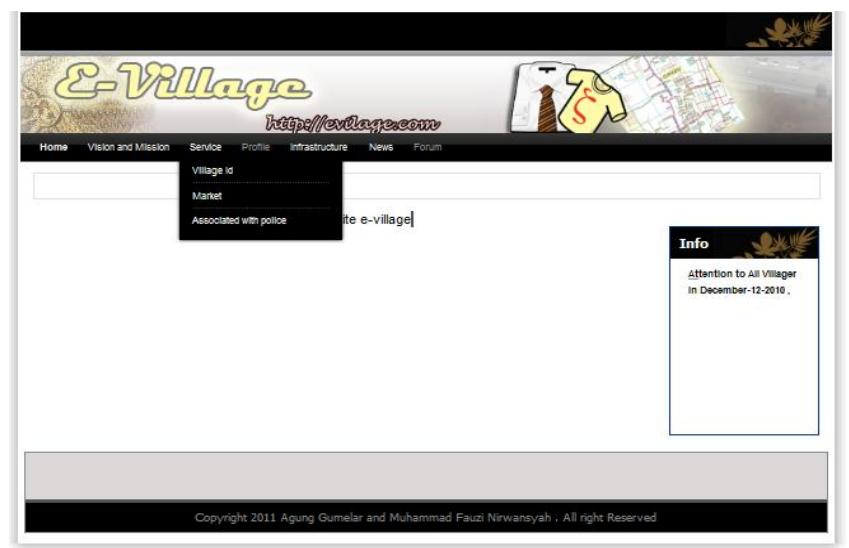

Fig. 2. This knowledge based web service for knowledge sharing purposes (example: current available services, policy and market).

In the case of our study, an online web-based communication in Cipadu will fill the gap between consumers and producers and find an easier way for consumers to communicate directly with sellers by using customer-to-provider or a business-to-business approach. In the global economies, business which run with web capability, make the CRM (customer relationship management) a much easier and accessible option. By using this type of web application, customers and sellers can watch when a piece of correspondence been submitted, what commitments were made to respond, when a response actually took place, who is handling the item. Fig. 2 shows the knowledge sharing for current available services, policy and market. Fig. 3 shows the sub menu of the Forum menu. The sub menu on Knowledge sharing, Knowledge transfer, Knowledge implementation and Knowledge creation are means for communication and sharing their information within Cipadu village people or other people outside Cipadu village, especially in mapping the market demands. Cipadu village people used SMS Gateway in their web service to allow the communication using sms from a mobile phone, as mostly the Cipadu people have and use mobile phone rather than computer.

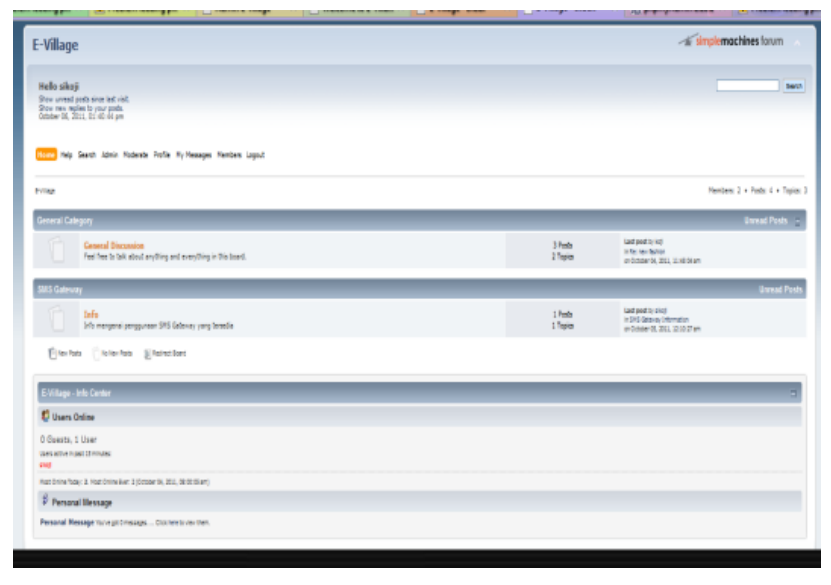

Fig. 3. The sub menu of those menu they need. such as knowledge sharing, knowledge transfer, knowledge implementation and knowledge creation.

\section{ImPaCt KNOWLEDGE ShaRing ON Village PEOPle STANDARD OF LIFE}

Innovation will be a success if the required information is available and the ability of the community to improve the competitiveness of the products has been available as well as a commitment from the community to continue to maintain the quality of the products they produce. According to statistical data from the Ministry of Industry Indonesia's textile exports from 2007 to 2011 continued to increase.

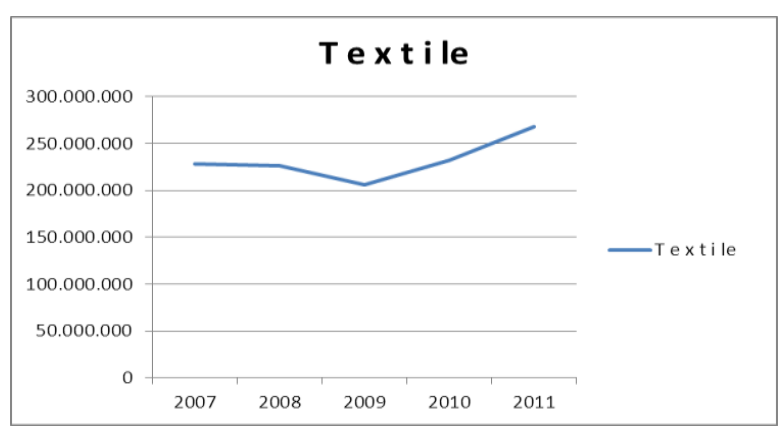

Fig. 4. Export textile product of Indonesia.

Information related to Indonesia's export commodities and regional marketing for textile commodity accessible when the public can find out the source of the information, availability and how to obtain information that is the main problem. With the web-based application in which there will be a discussion forum to create a knowledge sharing that information from the knowledge creator acceptable to the knowledge seeker. Fig. 4 above shows Indonesia's export 
commodities in the field of textiles continued to increase from 2007 to 2011, even in the year 2011 reached $\$ 267,825,826$. This is an opportunity for the community Cipadu to improve the quality of textile and textile product innovations on their product so that they can enter into the international market. Fig. 5 illustrates the processing of textile products in the form of coats for men and women. Knowledge is in Cipadu Cipadu will be an asset for itself, so with the knowledge that they have to improve their lives.

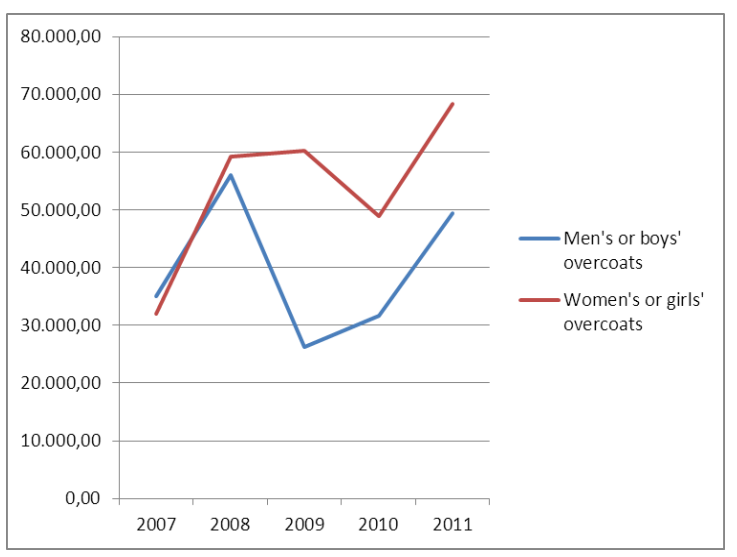

Fig. 5. Export of overcoat commodity of Indonesia.

\section{RESULT AND ANALYSIS}

The Cipadu village people need high quality human resources such as knowledge-based worker or knowledge-based human to formulate work performances and value-added, and as source of competitiveness. In the globalization era, "global village", give a challenge itself to Developing Countries network and human resources such as project designers and data interpreters who certainly are important knowledge sources [4]. On the other hand, computer or other systems generate substantial and significant knowledge contents.

The knowledge management must make provision for both, direct human knowledge and indirect human knowledge, as mediated by machines, which extend and enhance the powers of mind or tacit knowledge. Therefore, knowledge management is directed to the accessible and usefulness of enhancing their products into innovation. This is one of the usefulness of village database which data, information, and village knowledge easily accessed by everyone. Through externalization and internalization, in the Nonaka's Knowledge Cycle model, network becomes the core of the process [1]. By developing simple network, the people easily access outside knowledge and know how to develop value to the village. This knowledge could become skill knowledge. Skill knowledge worker knows how to do something of value [4]. This skill becomes the basis of core competencies for this village. By this valuable skill or knowledge, Cipadu citizen will follow the rapidly changing business environment, and then they will easily come to the market needs.

The market needs should become the people of Cipadu needs. They benefit it from this communication, since they receive valuable new information and they have the opportunity to create knowledge from the information they receive through daily communication. The building of web communications will focus on Groupware, which will help groups of people work together on creating valuable products and share information over a network. Groupware is a component of broad concept called workgroup computing, which includes network hardware and software that enables group members to communicate, manage projects, schedule meetings, and make group decisions [5]. A major feature of groupware is group scheduling, in which a group calendar is published in web-based communication to have a meeting. This meeting is a knowledge sharing which regularly conducted in the village and they should discuss in regard for finding solutions, with controversial issues, helping a group with many conflicts to work together, generating and prioritizing options, defining problems, reaching consensus, creating a performance record [5] and village potencies. This knowledge sharing could enhance village people welfare. This web-based communication is one of the tools for knowledge based to implement the Nonaka's knowledge cycles. Knowledge creation can be developed through this web-based communication, since they can develop a knowledge sharing between the knowledge holders and knowledge seekers [1]. The result of the village meeting or sharing knowledge will support the data and information by using the effective and efficient data communication. Data and information are used for supporting the development of new product or services, such as what will the market demand. Then, we expect that this village could become an entrepreneur village and their products or services become village competencies. Their knowledge sharing could be developed as knowledge culture in the village. When the innovation becomes a culture, The knowledge can be a source of innovation.

We also developed a Knowledge Management database. A Database is a collection of data organized in a manner that allows access, retrieval, and use of that data. A Knowledge Management database at a village contains data about the people of the village, the group of people and officer, NGO, and other groups of people in this village that carry out discussion in the village and the outcome of the discussion include knowledge that come out from the discussion and become a subject of knowledge sharing activity to other people in the village. Therefore, the databaase in this village should has a value. An organizations or village should review the information it produces to determine if it still cost-effective to produce. Sometimes, it is not easy to place value on information. For this reason, some organization or village create information only on demands, that is, people request it, instead of on regular basis. Many make information available online. Users then can access and print online information as they need it. For example, in Cipadu, sending printed benefits manual to each people in the village could be quite costly. Instead, the village people can access an online benefits manual, when they need to review it. Generally, users modify record in a file for two reasons: (1) to correct inaccurate data or (2) to update old data witrh new data. A more common reason to modify a record is to update old data with new data. Suppose, for example, that one people in the group moves to other village. The process to change the address and update the record might include display the people Maintenence Form, The Database 
Management Systems (DBMS) display data about the correct name of the people who moves and if should be modifies, the village employee who responsible to the database modify the record on the disk.

Database and DBMS is based on specific data model. A data model consists of rules and standards that define how the database organizes the data A data model defines how users view the organization of the data. It does not define how the operating system actually arranges the data on the disk Three popular data model in use today are relational, object oriented, and multidimensional. A database typically is based on one data model.

\section{A. Database e-Village}

One of the more features of the Web is the vast amount of information it provides. The Web offers information about knowledge of clothes, thread, process of easier make clothes, market information not only nationally but also internationally. Much of this and other information exists in databases that are stored on the Web or are accessible through the web. Some Web databases are collaborative databases, where users store and share photo, videos, recording of their discussion and other personal media with other registered users.

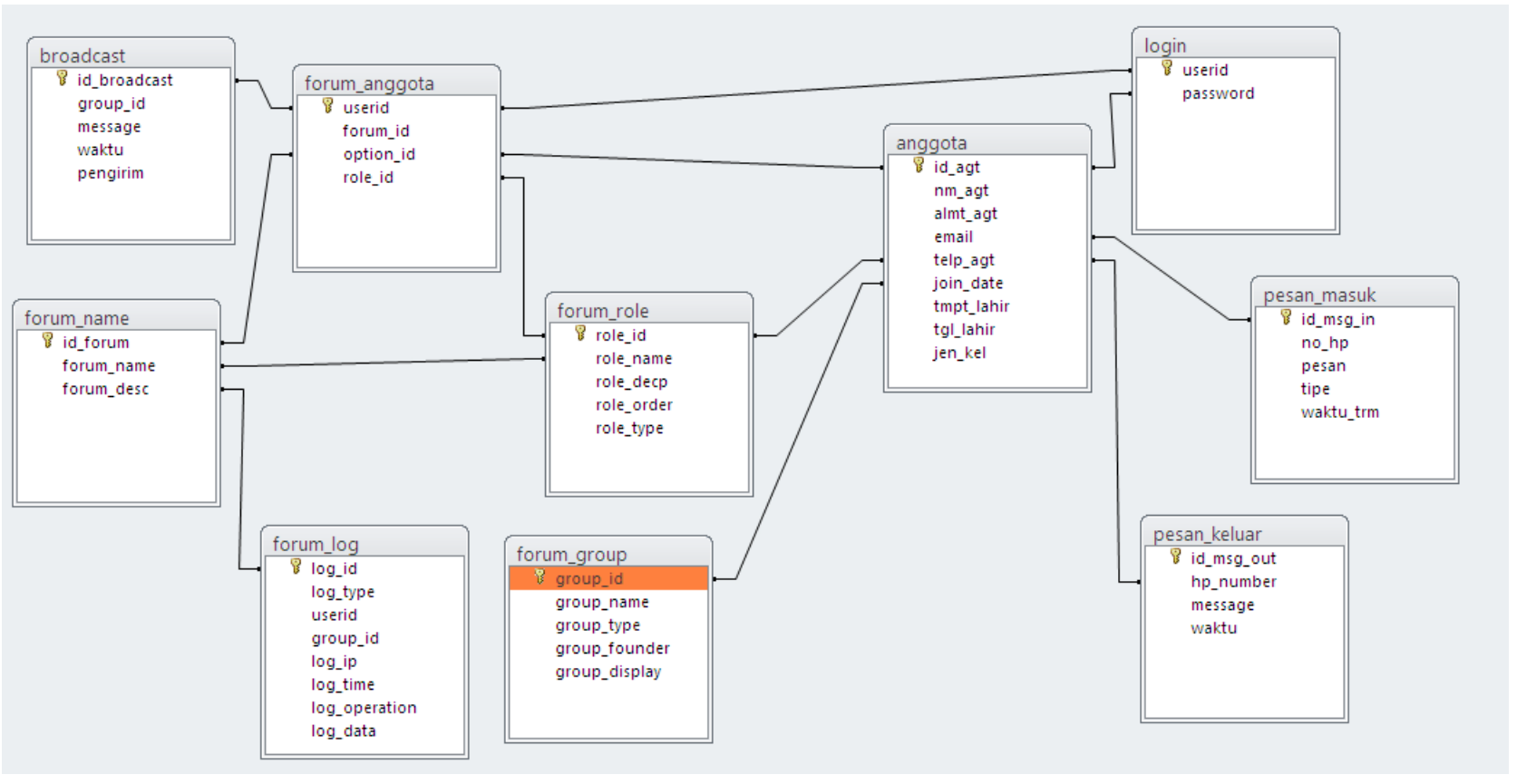

Fig. 6. Web database.

Fig. 6 show web database, to access data in a Web database, you fill a form or enter search text on a Web page. The Web page is the front end on to the dataabase. Many search engines auch as Yahoo! use databases to store Web site descriptions. Thus, the search engines's home page is the fron end to the database. To access the database, you enter search text into the search engine. A Web database usually resides on a database server. A database server is a computer that stores and provides access to a database. In addition to accessing information, users provide information to Web databases. Many Web sites request that users enter personal information such as name, address, telephone number, and preferences, into an e-form. The database then stores this personal information for future use. The village, may send e-mail messages to certain group of customers.

\section{A. Communication on Cipadu}

Computer communication describes a process in which two or more computer or devices transfer data, instructions and informationPlease note that the references at the end of this

Fig. 7 show a sample of communications system. Users can send and receive wireless messages to a from smart phones, and other mobile device and computer using wireless instant messaging, Since many village people at Cipadu do not have computer. Therefore, they mobile device.
The telephone is an integral part of computer communications. Data, instructions, and information are transmitted over the telephone network using dial-up lines or dedicated lines that use the telephone network for data communications. The network computers and devices that span multiple rooms or floors in a home, it may be more covinient to use a wireless strategy One advantage of wireless network is that you can take a mobile phone outside We also developed a Knowledge Management database. A Database is a collection of data organized in a manner that allows access, retrieval, and use of that data. A Knowledge Management database at a village contains data about the people of the village, the group of people and officer, NGO, and other groups of people in this village that carry out discussion in the village and the outcome of the discussion include knowledge that come out from the discussion and become a subject of knowledge sharing activity to other people in the village. Therefore, the databaase in this village should has a value. An organizations or village should review the information it produces to determine if it still cost-effective to produce. Sometimes, it is not easy to place value on information. For this reason, some organization or village create information only on demands, that is, people request it, instead of on regular basis. Many make information available online. Users then can access and print online information as they need it. For example, in Cipadu, 
sending printed benefits manual to each people in the village could be quite costly. Instead, the village people can access an online benefits manual, when they need to review it. Generally, users modify record in a file for two reasons: (1) to correct inaccurate data or (2) to update old data witrh new data. A more common reason to modify a record is to update old data with new data. Suppose, for example, that one people in the group moves to other village. The process to change the address and update the record might include display the people Maintenence Form, The Database Management Systems (DBMS) display data about the correct name of the people who moves and if should be modifies, the village employee who responsible to the database modify the record on the disk.

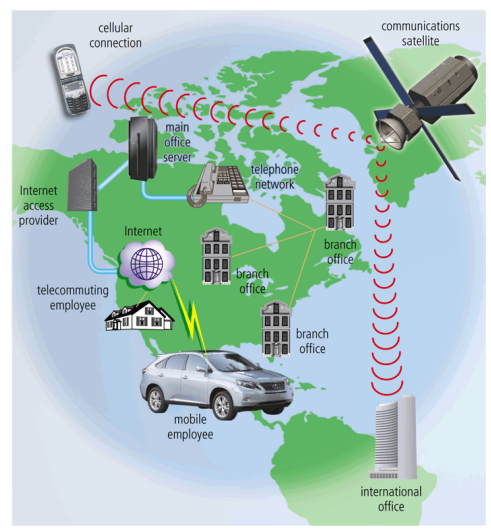

Fig. 7. Sample communication system

\section{CONCLUSION}

Cipadu village, as a famous village that produces materials for clothing, have a problem in introducing their products, share information and services. The village has no knowledge based application including the data communication, database and computer network. Their data and information are still stored manually. Web based knowledge sharing application in Cipadu village can be started as a potential village were use web based application for share information other village or agencies, introduce product and services. This study presents the web based application knowledge sharing for supporting Cipadu village uses a computer network and data communication such as sms gateway, in supporting knowledge management, including:

1) Knowledge transfer and Knowledge creation \& innovation

2) Web-based communication.

3) E-commerce Cipadu website

4) Database for storing and retrieve the knowledge

\section{REFERENCES}

[1] I. Nonaka and H. Takeuchi, The knowledge-creating company: how Japanese companies create the dynamics of innovation, Oxford: Oxford University Press, USA, Nov. 2007, pp. 120-122.

[2] G. B. Shelly, T. J. Cashman et al., Discovering Computers 2007, A gateway to Information, Web Enhanced Complete, Thomson Course Technology, Boston: Massachusetts, 2007, ch.9.

[3] A. Hussain and S. Qazi. (December 2010). Development of E-Village in Pakistan. IEEE Explore. [Online] pp. 242-246. Available: http://ieeexplore.ieee.org/xpl/login.jsp?tp=\&arnumber=5715782\&url =http $\% 3 \mathrm{~A} \% 2 \mathrm{~F} \% 2 \mathrm{Fieeexplore.ieee.org} \% 2 \mathrm{Fxpls} \% 2 \mathrm{Fabs} \_a l l . j s p \% 3 \mathrm{Far}$ number\%3D5715782

[4] T. Housel and A. Bell, Measuring and Managing Knowledge, The McGraw-Hill Book Co, Singapore, 2001, pp. 15-20.

[5] M. C. Rumizen, The Complete IDIOT'S Guide to Knowledge Management, CWL Publishing Enterprises, Madison: USA, 2002.

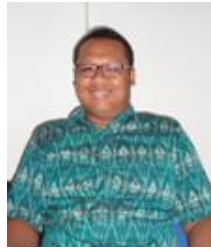

Dian Anubhakti was born in Malang, 22 January 2013. Bachelor of Computer Science University of Budi Luhur, Jakarta, Indonesia, 2004. Master of Computer Science University of Budi Luhur, Jakarta, Indonesia, 2010. LECTURER at Faculty of Information Technology, University of Budi Luhur, Jakarta, Indonesia 2004 - now. Proceeding of the 2011 2nd International Congress on Computer Applications and Computational Science, Berlin, Germany:Springer, 2011.

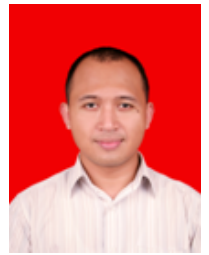

Basuki Hari Prasetyo was born in Jakarta, 1 Apri 1981. Bachelor of Computer Science University of Budi Luhur, Jakarta, Indonesia, 2003. Master of Computer Science University of Budi Luhur, Jakarta, Indonesia, 2008. LECTURER at Faculty of Information Technology, University of Budi Luhur, Jakarta, Indonesia 2003 - now. Proceeding of the 2011 2nd International Congress on Computer Applications and Computational Science, Berlin, Germany:Springer, 2011.

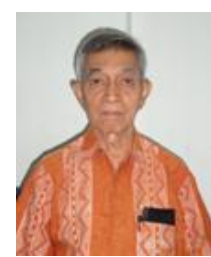

Nazir Harjanto was born in Jombang, 1 December 1939. Bachelor of Mathematics and Natural Science University of Indonesia, Jakarta, Indonesia, 1965. Master of Science University of Denver, Denver, Colorado, USA, 1984. RESEARCHER at Indonesian Institute of Science 1965 - 2005. VICE RECTOR for Research University of Budi Luhur 2002 - 2006. LECTURER at Faculty of Information Technology University of Budi Luhur, Bogor Agricultural University (IPB). Penerapan Knowledge Manajemen pada Organisasi, Jakarta, Indonesia:Graha Ilmu, 2009. Proceeding 3rd International Conference on Information and Communication Technology for the Moslem World (ICT4M), Jakarta, Indonesia:IEEE Indonesia Section, 2010. Proceeding of the 2011 2nd International Congress on Computer Applications and Computational Science, Berlin, Germany:Springer, 2011. 